\title{
PENERAPAN MODEL PEMBELAJARAN POINT-COUNTER-POINT BAGI MAHASISWA IKIP BUDI UTOMO MALANG
}

\author{
Dany Miftahul Ula \\ IKIP Budi Utomo Malang \\ dany.pssbu@gmail.com \\ Muhammad Naharuddin Arsyad. \\ IKIP Budi Utomo Malang \\ arsyadtsuki@gmail.com
}

\begin{abstract}
ABSTRAK
Tujuan dari tulisan ini adalah untuk mendiskusikan tentang model pembelajaran Point-Counter-Point. Model Pembelajaran Point-Counter-Point adalah suatu cara dalam proses pembelajaran yang memberikan kesempatan pada mahasiswa untuk aktif berargumen dalam mengajukan ide-ide atau gagasan dari permasalahan yang dimunculkan dalam pembelajaran sesuai dengan aturan-aturan yang ada. Sehingga diharapkan akan tercipta proses pembelajaran yang aktif dan pada akhirnya dapat meningkatkan hasil belajar mahasiswa. Penelitian ini bertujuan untuk untuk mengetahui efektivitas dan pengaruh penerapan model pembelajaran pointcounter-point terhadap hasil belajar mahasiswa prodi pendidikan sejarah dan sosiologi di IKIP Budi Utomo Malang. Jenis penelitian yang digunakan adalah penelitian eksperimen, dengan desain one group pretest posttest. Penelitian ini menggunakan instrumen observasi, dokumentasi dan tes yang akan dianalisis secara kuantitatif. Hasil penelitian menunjukkan bahwa hasil post-test lebih besar daripada pre-test, yakni $(76,78>67,78)$ dan berdasarkan hasil uji-t Paired Samples Test Didapatkannya hasil - t-hitung < - t-tabel $(-7,398<-2,01537)$. Thitung bernilai negatif berarti nilai rata-rata pre-test lebih rendah dari pada nilai rata-rata post-test. Dan karena nilai sig. (2-tailed) sebesar 0,000 lebih besar dari 0,05 maka H0 ditolak dan H1 diterima. Sehingga dapat disimpulkan bahwa penerapan model pembelajaran point counter point dapat meningkatkan hasil belajar mahasiswa prodi sejarah dan sosiologi IKIP Budi Utomo Malang.
\end{abstract}

Kata kunci: Model, Pembelajaran, Point-Counter-Point

\begin{abstract}
The purpose of this paper is to discuss the Point-Counter-Point learning model. Point-Counter-Point Learning Model is a way in the learning process that provides opportunities for students to actively argue in proposing ideas or ideas from problems raised in learning in accordance with existing rules. So that it is expected to create an active learning process and ultimately be able to improve student learning outcomes. This study aims to determine the effectiveness and influence of the implementation of learning models point-counter-points on learning outcomes of students of history education and sociology study program at IKIP Budi Utomo Malang. The type of research used is experimental research, with the design of one group pretest posttest. This study uses observation instruments, documentation and tests that will be analyzed quantitatively. The results showed that the results of the post-test were greater than the pre-test,
\end{abstract}


namely (76.78> 67.78) and based on the Paired Samples Test t-test results obtained - t-count <- t-table $(-7,398<-2,01537)$. T-count is negative, meaning the average pre-test value is lower than the post-test average value. And because of the sig value. (2-tailed) of 0,000 greater than $0.05, \mathrm{H} 0$ is rejected and H1 is accepted. So it can be concluded that the application of the counter point learning model can improve the learning outcomes of students of the history and sociology study program of IKIP Budi Utomo Malang

Keyword: Model, Learning, Point-Counter-Point

\section{PENDAHULUAN}

\section{Pendidikan adalah suatu usaha yang} dilakukan sadar dan terencana untuk mewujudkan suasana dan proses pembelajaran yang aktif bagi peserta didik agar mampu mengembangkan potensi yang ada di dalam dirinya, seperti kepribadian yang baik, pengendalian diri, berakhlak mulia, kecerdasan,dan keterampilan yang diperlukan oleh dirinya dan masyarakat. Dari pengertian tersebut sudah terlihat bahwa pendidikan merupakan suatu proses yang penting dalam kehidupan untuk mengetahui kemampuan dan tingkah laku masing-masing peserta didik dalam melakukan hal baik ataupun hal buruk. Di Indonesia khususnya di bidang pendidikan mulai ditingkatkan, salah satunya penggunaan strategi dalam KBM.

Sampai sekarang kebanyakan pendidik hanya menggunakan metode tradisional yang penyampaiannya sangat monoton bahkan membosankan, Sehingga proses pembelajaran bisa mematikan kreatifitas dan keaktifan peserta didik. Maka dari itu pendidik harus memiliki pengetahuan yang cukup mengenai model pembelajaran dalam mengajar, model atau strategi yang dapat membangkitkan atau menggugah gairah dan keaktifan peserta didik dalam proses pembelajaran sangatlah banyak dan salah satunya adalah model pembelajaran pointcounter-point.

Point-counter-point artinya saling beradu pendapat sesuai dengan perspektif, strategi ini merupakan satu teknik untuk merangsang diskusi danmendapatkan pemahaman yang lebih mendalam tentang berbagai isu komplek (sutrisno, 2015:98).Tujuan penerapan strategi point-counter-pointadalah untuk melatih peserta didik agar mencari argumentasi yang kuat dalam memecahkan suatu masalah yang aktual di masyarakat sesuai dengan posisi yang diperankan (Ismail, 2008:79). Jadi, model pembelajaran point-counterpointadalah suatu model pembelajaran yang dilakukan dengan cara memberikan kesempatan kepada mahasiswa untuk aktif berargumen (mengajukan ide-ide, gagasan) dari persoalan yang muncul atau sengaja dimunculkan dalam pembelajaran sesuai dengan aturan-aturan yang ada.

Disini peneliti lebih tertarik untuk membahas tentang model pembelajaran pointcounter-point karena strategi ini adalah strategi yang bisa mengaktifkan peserta didik dan memberi kebebasan pada mereka untuk berargumen atau mengajukan ide-ide dari persoalan yang muncul atau sengaja dimunculkan dalampembelajaran sesuai dengan 
aturan-aturan yang ada. Dan dengan diterapkannya model pembelajaran tersebut dapat menjadikan peserta didik semakin aktif dan kreatif dalam mengikuti proses pembelajaran serta semakin kritis terhadap permasalahan permasalahan yang ada. Khususnya permasalahan yang dipelajari dalam mata kuliah sosiologi pendidikan. Berdasarkan latarbelakang tersebut, penulis ingin meneliti lebih jauh tentang penerapan model pembelajaran point-counterpoint dan pengaruhnya terhadap hasil belajar mahasiswa IKIP budi utomo malang. Adapun objek penelitian ini adalah mahasiswa jurusan pendidikan sejarah dan sosiologi angkatan 2017 IKIP Budi Utomo Malang.

\section{METODE}

Model penelitian yang diajukan oleh peneliti adalah eksperimen. Hal ini karena peneliti sengaja memunculkan sesuatu kejadian atau keadaan kemudian diteliti bagaimana akibatnya. Desain atau rancangan eksperimen yang digunakan adalah one group pretest posttest design. Subjek penelitian adalah mahasiswa jurusan Pendidikan Sejarah dan Sosiologi. Populasi dalam penelitian ini adalah mahasiswa angkatan 2017 sebanyak 3 kelas. Teknik pengambilan sampel yang digunakan dalam penelitian ini yaitu purposive sampling. Dari teknik tersebut sampel yang terpilih adalah kelas A angkatan 2017 sebanyak 45 mahasiswa. Teknik pengumpulan data adalah cara atau teknik yang digunakan penulis untuk mendapatkan data atau informasi yang dapat dipertanggungjawabkan kebenarannya sesuai dengan kenyataan. Adapun teknik yang digunakan dalam pengumpulan data penelitian ini adalah observasi, dokumentasi dan tes. Dan dalam penelitian ini menempuh beberapa tahapan sebagai berikut: (1) Menentukan subjek penelitian dengan cara memilih satu kelas dari seluruh kelas angkatan 2017 prodi pendidikan sejarah dan sosiologi (2) Memberikan pretest untuk mengukur kemampuan subjek sebelum diajar dengan model pembelajaran pointcounter-point. (3) Memberikan treatment (perlakuan) yaitu model pembelajaran pointcounter-point (4) Memberikan posttest untuk mengukur kemampuan subjek sesudah diajar dengan model pembelajaran point-counter-point. (5) Menghitung hasil pretest dan posttest untuk menentukan perbedaan yang muncul (6) Menganalisis data untuk mengetahui perbedaan hasil belajar sebelum dan sesudah penerapan model pembelajaran point-counter-point.

\section{HASIL DAN PEMBAHASAN}

1. Penerapan Model Pembelajaran Point Counter Point Pada Mata Kuliah Sosiologi Pendidikan

Penerapan model pembelajaran Point Counter Point dilaksanakan pada tanggal 17 Desember $\rightarrow$ dan berikut ini adalah hasil penerapan model pembelajaran tersebut yang telah diamati oleh peneliti.

\section{Tabel 1.Hasil observasi aktivitas belajar mahasiswa}

\begin{tabular}{|c|c|c|c|c|c|c|c|}
\hline \multirow[t]{2}{*}{ No } & \multirow[t]{2}{*}{ Aspek yang Dinilai } & \multicolumn{5}{|c|}{ Skor } & \multirow{2}{*}{$\begin{array}{c}\text { Skor } \\
\text { Indikator }\end{array}$} \\
\hline & & 1 & 2 & 3 & 4 & 5 & \\
\hline 1 & Kesiapan mahasiswa menerima pel & aran & & & & & $85 \%$ \\
\hline $\mathbf{a}$ & Masuk kelas tepat waktu & & & & $\sqrt{ }$ & & \\
\hline b & $\begin{array}{l}\text { Menyiapkan perlengkapan untuk } \\
\text { berdiskusi }\end{array}$ & & & & $\sqrt{ }$ & & \\
\hline
\end{tabular}




\begin{tabular}{|c|c|c|c|}
\hline c & $\begin{array}{lll}\begin{array}{l}\text { Berdo'a } \\
\text { dimulai }\end{array} & \text { sebelum } & \text { pelajaran } \\
\end{array}$ & $\sqrt{ }$ & \\
\hline 2 & Antusias Mahasiswa Selama proses pembelajaran & & $90 \%$ \\
\hline $\mathbf{a}$ & $\begin{array}{l}\text { Menyimak seluruh informasi yang } \\
\text { disampaikan oleh dosen }\end{array}$ & $\sqrt{ }$ & \\
\hline b & $\begin{array}{l}\text { Mencari kelompok yang sudah } \\
\text { ditentukan }\end{array}$ & $\sqrt{ }$ & \\
\hline c & $\begin{array}{l}\text { Mencatat materi yang telah } \\
\text { diberikan }\end{array}$ & $\sqrt{ }$ & \\
\hline d & $\begin{array}{l}\text { Bekerja sama dalam kelompoknya } \\
\text { masing-masing }\end{array}$ & $\sqrt{ }$ & \\
\hline 3 & Aktivitas mahasiswa selama proses pembelajaran & & $80 \%$ \\
\hline $\mathbf{a}$ & $\begin{array}{l}\text { Memahami materi yang diberikan } \\
\text { bagi kelompok yang telah } \\
\text { ditentukan }\end{array}$ & & \\
\hline b & $\begin{array}{l}\text { Masing-masing kelompok } \\
\text { menyiapkan argumen sesuai } \\
\text { dengan padangan keompok yang } \\
\text { diwakili }\end{array}$ & $\sqrt{ }$ & \\
\hline c & $\begin{array}{l}\text { Perwakilan dari masing-masing } \\
\text { kelompok mulai diskusi / } \\
\text { perdebatan dimulai }\end{array}$ & $\sqrt{ }$ & \\
\hline d & $\begin{array}{l}\text { Setiap kelompok membandingkan } \\
\text { hasil pekerjaan mereka sema. }\end{array}$ & $\sqrt{ }$ & \\
\hline 4 & $\begin{array}{l}\text { Partisipasi mahasiswa dalam menurup } \\
\text { pembelajaran }\end{array}$ & kegiatan & $85 \%$ \\
\hline $\mathbf{a}$ & $\begin{array}{llr}\text { Memperbaiki } & \text { atau } & \text { menambah } \\
\text { kesimpulan } & \text { dari } & \text { kelompok } \\
\text { masing-masing } & & \end{array}$ & $\sqrt{ }$ & \\
\hline b & $\begin{array}{lcc}\text { Mencatat kesimpulan atau } \\
\text { rangkuman } \\
\text { masing-masing mahasiswa }\end{array}$ & $\sqrt{ }$ & \\
\hline c & $\begin{array}{l}\text { Kembali ke tempat duduk lalu } \\
\text { berdo'a. }\end{array}$ & $\sqrt{ }$ & \\
\hline
\end{tabular}

\begin{tabular}{ll}
\hline Jumlah & $\mathbf{8 5 \%}$
\end{tabular}

pembelajaran point counter point. Evaluasi

Berdasarkan tabel tersebut bisa diambil kesimpulan bahwa aktivitas belajar dari mahasiswa tergolong dalam kategori aktif karena berdasarkan dari hasil persentase yang menunjukkan sebesar $85 \%$. Hal ini menunjukkan bahwa penerapan model pembelajaran point counter point pada mata kuliah sosiologi pendidikan telah dilaksanakan dan menunjukkan kategori yang aktif.

Selanjutnya, peneliti melakukan penilaian untuk mengetahui tentang keberhasilan dalam penerapan model dilakukan dengan cara uji lapangan. Uji lapangan bertujuan untuk mengetahui ketercapaian tujuan penerapan model pembelajaran yang berupa peningkatan hasil belajar, oleh kerena itu, dilakukan post-test dan kemudian dibandingan dengan hasil yang diperoleh sebelum menggunakan model pembelajaran yaitu berupa pre-test. Dan berikut ini adalah tabel hasilnya. 
Tabel 2. Nilai Tes mahasiswa sebelum dan sesudah diterapkan model pembelajaran point counter point

\begin{tabular}{cccc}
\hline Keterangan & \multicolumn{2}{c}{ Nilai Mahasiswa } & Gain \\
\cline { 2 - 3 } & Pre-test & Post-test & (d) \\
\hline Nilai total & 3050 & 3455 & 405 \\
\hline Rata - rata & 67,78 & 76,78 & 9 \\
\hline \multicolumn{3}{c}{ (Sumber : Dokumentasi } \\
\\
\\
& Peneliti)
\end{tabular}

Berdasarkan tabel tersebut, dapat diketahui bahwa hasil rata-rata pre-test dan post-test mahasiswa berbeda. Hasil perolehan nilai rata - rata pre-test mahasiswa adalah 67,78 sedangkan hasil post-test mahasiswa adalah $76,78 \mathrm{Hal}$ ini menunjukkan bahwa nilai post-test lebih baik daripada nilai pre-test yaitu $(76,78>$ 67,78). Secara umum mahasiswa mengalami peningkatan hasil belajar rata rata sebesar 9. Sehingga bisa disimpulkan bahwa penerapan model pembelajaran Point Counter Point Pada Mata Kuliah Sosiologi Pendidikan dapat meningkatkan hasil belajar mahasiswa prodi sejarah dan sosiologi IKIP Budi Utomo Malang.

2. Pengaruh model pembelajaran PointCounter-Point pada matakuliah sosiologi pendidikan terhadap hasil belajar mahasiswa.
Dan untuk lebih memperkuat hasil penelitian tentang pengaruh penerapan model pembelajaran Point-Counter-Point terhadap hasil belajar mahasiswa, maka dilakukan analisis uji-t yaitu paired sample test untuk mengetahui apakah peningkatan hasil belajar tersebut terjadi secara signifikan. Dan hipotesisnya sebagai berikut

H1 : Terdapat perbedaan yang signifikan pada hasil belajar mahasiswa sebelum dan sesudah menggunakan model pembelajaran Point-Counter-Point

$\mathrm{HO}$ : Tidak terdapat perbedaan yang signifikan pada hasil belajar mahasiswa sebelum dan sesudah menggunakan model pembelajaran Point-Counter-Point

Sebelum dianalisis, terlebih dahulu dilakukan uji normalitas data nilai pre-test dan nilai post-test. Normalitas data nilai hasil tes dalam penelitian ini adalah persyaratan yang harus dipenuhi untuk melakukan analisis inferensial dengan menggunakan teknik statistik parametrik. Hasil pengujian terhadap hasil belajar mahasiswa dilakukan dengan menggunakan program SPSS 14.

Tabel 3. One-Sample Kolmogorov-Smirnov Test

\begin{tabular}{|c|c|c|c|}
\hline & & Pre_Test & Post_Test \\
\hline \multicolumn{2}{|c|}{$\mathrm{N}$} & 45 & 45 \\
\hline \multirow[t]{2}{*}{$\begin{array}{c}\text { Normal } \\
\text { Parameters }(\mathrm{a}, \mathrm{b}) \\
\end{array}$} & Mean & 67,7778 & 76,7778 \\
\hline & Std. Deviation & 11,60699 & 7,24220 \\
\hline \multirow[t]{3}{*}{$\begin{array}{l}\text { Most Extreme } \\
\text { Differences }\end{array}$} & Absolute &, 176 &, 153 \\
\hline & Positive & ,089 &, 153 \\
\hline & Negative &,- 176 &,- 130 \\
\hline \multicolumn{2}{|c|}{ Kolmogorov-Smirnov Z } & 1,180 & 1,023 \\
\hline
\end{tabular}


a Test distribution is Normal.

Asymp. Sig. (2-tailed) $\quad, 123 \quad, 246$

b Calculated from data.

(Sumber : Dokumentasi Peneliti)

Hasil uji normalitas dengan menggunakan one sample kolmogorovsmirnov test terhadap nilai pre-test dan nilai post-test mahasiswa prodi pendidikan sejarah dan sosiologi IKIP Budi Utomo Malang yang ditunjukkan pada tabel tersebut diperoleh nilai signifikan lebih besar dari 0,05 yaitu pre-test sebesar 0,123 dan post-test sebesar 0,246 Nilai tersebut lebih besar dari taraf nyata 0,05 yakni $(0,123$ dan $0,246>0,05)$, hal ini berarti bahwa subjek penelitian berdistribusi secara normal dan syarat untuk melakukan analisis uji-t (Paired Sample Test) telah terpenuhi.
Langkah selanjutnya adalah menganalisis data nilai pre-test dan posttest yang dilakukan dengan uji-t (Paired Sample Test). Hal ini dilakukan untuk mengetahui, apakah terjadi perbedaan yang signifikan antara nilai rata-rata mahasiswa sebelum dengan sesudah mengikuti pembelajaran dengan menggunakan model pembelajaran Point-Counter-Point. Uji-t (Paired Sample Test) dilakukan dengan menggunakan SPSS 14 dengan taraf kepercayaan 95\% (signifikansi 0,05), hasil uji t Paired Sample Test dapat dilihat pada Tabel berikut ini.

\section{Tabel 4. Paired Samples Test}

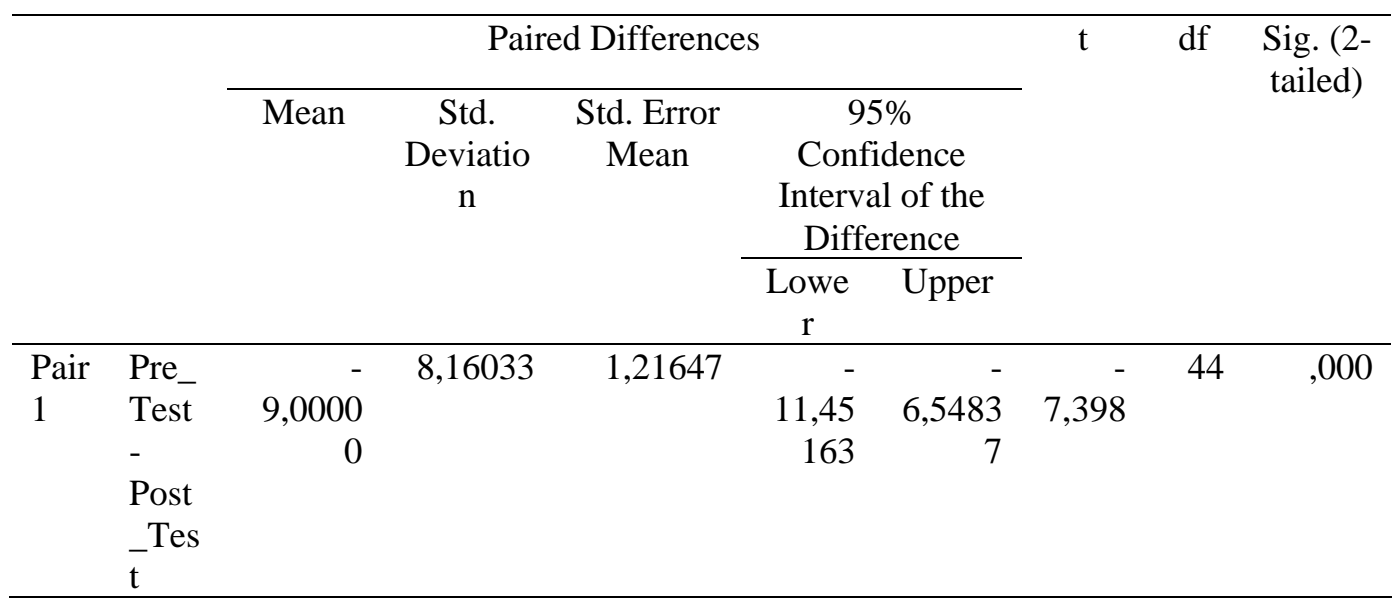

(Sumber : Dokumentasi Peneliti)

Berdasarkan tabel tersebut diketahui bahwa nilai t-hitung diperoleh sebesar 7,398 dan untuk t-tabel diperoleh dengan cara $\alpha=5 \% / 2=2,5 \%$ (untuk uji 2 sisi) dengan derajat kebebasan (df) n-1 atau 45-1 $=44$. Pengujian 2 sisi ( signifikansi $=$ 0,025) hasil diperoleh untuk t-tabel pada 2,01537 dengan taraf signifikan 0,025.
Didapatkannya hasil - t-hitung < - t-tabel $(-$ 7,398 <-2,01537). T-hitung bernilai negatif berarti nilai rata-rata pre-test lebih rendah dari pada nilai rata-rata post-test. Dan karena nilai sig. (2-tailed) sebesar 0,000 lebih besar dari 0,05 maka dapat disimpulkan bahwa H0 ditolak dan H1 diterima. 
Sehingga berdasarkan uraian tersebut dapat diartikan bahwa terdapat perbedaan yang signifikan antara hasil belajar mahasiswa sebelum dan setelah penerapan model pembelajaran Point-Counter-Point pada mata kuliah sosiologi pendidikan dan ditarik kesimpulan bahwa penerapan model pembelajaran Point-Counter-Point mampu secara efektif meningkatkan hasil belajar mahasiswa angkatan 2016 kelas A program studi pendidikan sejarah dan sosiologi FPISH IKIP Budi Utomo Malang.

\section{KESIMPULAN}

Berdasarkan landasan teori dan didukung oleh analisis data hasil uji instrumen penelitian, maka dapat disimpulkan sebagai berikut:

1. Penerapan model pembelajaran point counter point pada mata kuliah sosiologi pendidikan telah dilakukan dan berhasil meningkatkann motivasi belajar mahasiswa IKIP Budi Utomo Malang.

2. Pembelajaran yang dilaksanakan dengan menerapkan model pembelajaran point counter point pada mata kuliah sosiologi pendidikan bisa meningkatkan hasil belajar mahasiswa prodi pendidikan sejarah dan sosiologi pada mata kuliah sosiologi pendidikan.

\section{REFERENSI}

\author{
Abu Ahmadi. (2000). Sosiologi Pendidikan.PT \\ Adi Mahasatya : Jakarta \\ Ary H.Gunawan. (2000). Sosiologi \\ Pendidikan.PT Rhineka Cipta: Jakarta.
}

Cholil \& Kurniawan, Sugeng. (2011). Psikologi Pendidikan: Telaah Teoritik dan Praktik. IAIN Sunan Ampel Press : Surabaya.

Ismail. (2008).Strategi Pembelajaran Agama Islam Berbasis PAIKEM RASAIL MediaGroup :Semarang

Marno dan M.Idris. (2008). Strategi Dan Metode Pengajaran Menciptakan Ketrampilan MengajarYang Efektif Dan Edukatif.ArRUZZ : Jogjakarta

Rusman. (2012). Belajar dan Pembelajaran Berbasis Komputer. Alfabeta : Bandung

Sugiyono. (2014). Metode Penelitian Kuantitatif Kualitatif Dan $R \& D$. Alfabeta: Bandung.

Suharsimi Arikunto. (2012). Prosedur Penelitian Suatu Pendekatan Praktek Rineka Cipta :Jakarta.

Suharsimi Arikunto. (2013). Dasar-Dasar Evaluasi.Bumi Aksara : Jakarta:

Sutrisno Hadi, (2011). Metodologi Reseac. Andi Offset :Yokyakarta

Sutrisno. (2015). Revolusi Pendidikan Di

Indonesia Membedah Metode Dan Teknik

PendidikanBerbasis Kompetensi. Ar-RUZZ

:Jogjakarta 
